VARIA 


\section{Profecia e metarreflexividade: a figura de Proteu na encenação épica da poesia no Renascimento português}

Roger Friedlein

Universidade de Bochum (Alemanha)

\section{Introdução}

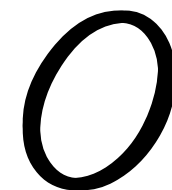

deus oceânico Proteu é uma figura mitológica de relevância considerável para a poesia épica portuguesa do Renascimento. Essa relevância despreende-se não apenas da sua presença n'Os Lusíadas, onde faz a sua aparição no episódio da Ilha dos Amores. Além disso, ocupa uma posição central no Naufrágio de Sepúlveda, de Jerónimo de CorteReal, e é o protagonista do único poema épico renascentista em língua portuguesa do Brasil, a Prosopopeia, de Bento Teixeira. ${ }^{1}$ Para além dessa presença quantitativa, já por si considerável, a significação do velho deus barbudo reside na sua função de figura-chave para a dimensão autorreflexiva dos poemas mencionados. O objetivo duplo deste artigo é, portanto, situar as diferentes versões da figura de Proteu na épica portuguesa no

\footnotetext{
${ }^{1}$ Anterior a ele é conhecido o poema épico latim De gestis Mendi de Saa (Coimbra, 1563) de José de Anchieta, que tradicionalmente tem sido excluído do percurso da literatura brasileira. SILVA; RAMALHO, 2007, estr. 82.
} 
panorama dos modelos poéticos que oferece a literatura italiana coetânea, e, por outro lado, demonstrar o potencial autorreflexivo dessa figura.

O deus marinho Proteu é conhecido, em primeiro lugar, através de três textos da Antiguidade clássica: ele surge num episódio da Odisseia e no final das Georgica de Virgílio, ${ }^{2}$ e ambas as vezes é mencionado o costume do velho deus de sair do mar ao meio-dia e de descansar no meio do rebanho de focas que ele pastoreia para o seu senhor Netuno. Se Proteu for preso naquele momento de repouso, e nunca solto apesar das múltiplas transformações da sua aparência externa de que ele é capaz, então ele volta para a sua aparência original de velho barbudo e dá resposta, também profética, às questões que se lhe colocam. Esses dons de transformar-se e de conhecer tudo que é, já foi ou será serão doravante as maiores características dele. Nas Metamorfoses de Ovídio, terceiro texto clássico de referência além da Odisseia e das Georgica, Proteu surge sobretudo dotado da sua capacidade profética, quando revela para Peleu a maneira dele forçar Tétis para conseguir fazer dela a sua

${ }^{2}$ Eidothea, a filha de Proteu, conta a Menelau as capacidades de vidente de seu pai, e fornece a Menelau e seus companheiros peles de foca para se esconderem e se apoderarem de Proteu apesar das múltiplas transformações. Assim desvela a Menelau o caminho de regresso para casa, bem como a sorte de Ulisses cativo na ilha de Calipso. HOMERO, Odisseia IV, estr. 365-570. A ninfa Cirene comunica a Aristeu que Proteu pode informar-lhe acerca do motivo da doença que atingiu o seu enxame de abelhas. Aristeu apodera-se dele, Proteu relata a história de Orfeu ofendido e vai-se embora no mar. Então Cirene informa Aristeu da maneira dele reconciliar-se com Orfeu irado e com as ninfas por meio de um sacrifício de bois. De dentro do corpo dos animais sacrificados é que aparecerá um novo enxame de abelhas para Aristeu. VIRGÍlLIO, Georgica IV, estr. 387-558. 
mulher. ${ }^{3}$ Dentro do mundo da narração, as profecias proferidas por Proteu nestes três exemplos clássicos são sempre contadas por ele em prosa: o Proteu da Antiguidade não canta, e a forma métrica dos três textos não vai mais além de ser um fenômeno do discours. Proteu não é, portanto, na Antiguidade associado com canto profético, mas unicamente com o conhecimento das coisas ausentes ou vindouras. Mesmo assim, vários elementos dos relatos homérico, virgiliano e ovidiano associam-no com temáticas metapoéticas. Através do motivo do vaticínio, Proteu fica associado à questão da veracidade dos relatos, e daí à verdade sob o velame da ficção. Além disso, no relato virgiliano é ele que profere a história do arquipoeta Orfeu. Finalmente a sua dedicação de guardador de rebanhos - ainda que marinhos - e a participação na história do apicultor Aristeu lhe dão certa proximidade do mundo bucólico que é metapoético já em $\mathrm{si}^{4}{ }^{4}$ Será na última grande epopeia da Antiguidade, nas Dionisíacas, de Nono de Panópolis, que Proteu atinge uma função expressamente poetológica quando no proêmio épico, o narrador invoca a sua presença nas suas formas várias para propor temáticas épicas adequadas a cada uma delas. ${ }^{5}$

${ }^{3}$ Proteu profetiza para Tétis que será mãe de um filho que superará em virtude o pai dele. Então Júpiter renuncia à sua união com Tétis. Peleu, no entanto, tenciona possuir Tétis, mas abandona esse intento após várias autotransformações dela. Atraído por uns sacrifícios para as divinidades marinhas, Proteu informa Peleu dele ter que atar Tétis e esperar até o fim das transformações para poder se apoderar dela. Assim sucede, e Tétis será mãe de Aquiles. OVÍDIO, Metamorfoses XI, p. 221-265.

${ }^{4}$ A constante dimensão metarreflexiva da poesia bucólica desde a Antiguidade até o Barroco italiano fica demonstrada em NELTING, 2007.

${ }^{5}$ NONNOS DE PANOPOLIS, 1976, p. 46 s. 
Giovanni Boccaccio na sua faceta de mitógrafo de referência do primeiro Renascimento salienta as capacidades proféticas de Proteu definindo-o nas Genealogie deorum gentilium (VII, 9) como

[...] senem atque circumspectum virum, et rerum experientia doctissimum, et eo quod animadversione sua nedum presentia nosceret, et integram preteritorum haberet memoriam, sed per coniecturas etiam preteritorum non nunquam, et sepe faciunt sapientes, de futuris predicebat eventum. ${ }^{6}$

Além das capacidades de sabedor e profeta são as contínuas transformações protéicas que merecem uma interpretação moralizante da parte de Boccaccio, sendo entendidas como significando as paixões às quais o homem está submetido. Esses breves traços já assentam a base para as leituras concorrentes da figura de Proteu. Após a sua primeira formulação na literatura italiana, elas iriam evoluir na épica renascentista de língua portuguesa.

\section{Os modelos protéicos na poesia épica italiana}

Ainda antes da formulação das duas versões decisivas do mito de Proteu, a figura do deus oceânico foi entendida por Pico della Mirandola de um modo particular. Pico usa a figura de Proteu como imagem para o homem, e por extensão pela humanidade no seu famoso discurso De dignitate hominis (1486).

6 "Fu un vecchio molto avveduto e dottissimo per esperienza di fatti, poiché non conosceva per l'osservazione, o per la presenza, o per la memoria integra del passato, bensì per congettura, anche delle cose passate e, come spesso fanno i sapienti, talora prediceva il futuro". BOCCACCIO, 1998, p. 730 s. 
Para Pico, o homem iguala-se na sua potencial variabilidade ao camaleão, mas também a Proteu na sua capacidade admirável de contínua transformação:

Quis hunc nostrum chamaleonta non admiretur? aut omnino quis aliud quicquam admiretur magis? Quem non immerito Asclepsius Atheniensis versipellis huius et se ipsam transformantis naturae argumento per Proteum in mysteriis significari dixit. Hinc illae apud Hebraeos et Pythagoricos metamorphoses celebratae. ${ }^{7}$

Deste modo, o Proteu de Pico della Mirandola, sem ser ele próprio o objeto da reflexão, e sem aparecer numa ficção narrativa, fica por meio da comparação do homem com ele, contaminado também das demais características desse homem civilizador e sabedor, desenhado no De dignitate hominis. ${ }^{8}$ Entre os autores da península ibérica, é Juan Luis Vives na sua Fabula de homine (1518) quem desenvolveu essa ideia, quando o homem protagonista da Fabula, graças à sua capacidade protéica de representar o papel teatral de qualquer elemento da criação e até mesmo dos deuses, é admitido como recompensa na companhia deles. Aqui também, no sentido inverso da comparação, podese dizer que o Proteu do valenciano Vives é associado à figura de um ator. Outros humanistas usam a comparação com Proteu para falar não só do homem, mas especificamente do poeta e

7 "Qui n'admirerait notre caméléon? Ou, d'une manière plus générale, qui aurait pour quoi que ce soit d'autre davantage d'admiration? Asclépios d'Athènes n'a pas eu tort de dire que les mystères, en raison de sa nature changeante et susceptible de se transformer elle-même, on désigne cet être par Protée. De là les métamorphoses célébrées chez les Hébreux et les pythagoriciens". PICO DELLA MIRANDOLA, 1993, p. 8-11.

${ }^{8}$ Cf. GIAMATTI, 1968, e também OSKIAN, 2004. 
sua mutabilidade: conforme à fórmula "poeta Proteus alter" ela surge, por exemplo, numa carta de Giovanni Pontano a Il Galateo. ${ }^{9}$ Nesses exemplos humanísticos, Proteu serve porém como comparação num contexto argumentativo, o qual sugere novos aspectos para a figura protéica, mas não implica uma plasmação narrativa dela.

\subsection{Sannazaro}

A interpretação renascentista de mais peso do mito de Proteu é devida a Jacopo Sannazaro na sua obra latina. No poema longo De partu virginis (Nápoles, 1526) sobre o nascimento de Jesus, Sannazaro faz terminar cada um dos três cantos do poema numa profecia. Após o Rei David no primeiro canto, e São José no segundo, será uma profecia de Proteu que encerra o terceiro canto. Ela é proferida pelo Rio Jordão personificado, também porque é para ele que Proteu tinha vaticinado uma posição excelente entre os rios do mundo quando tiver chegado aquele Messias que obrará milagres e reunirá apóstolos à volta dele. Marc Deramaix reparou na diferença decisiva entre a profecia do Rei David e a de Proteu: enquanto David vaticina em primeiro lugar os aspetos transcendentais como a redenção dos pecados, Proteu foca a estada terrena e a obra de Cristo na Terra:

Dans le De partu Virginis, David perçoit la providence tandis que Protée perçoit le destin et la nature. Cette perceptioni propre à Protée est inséparable du temps [...] Si la révélation soudaine de la Rédemption dans la tradition biblique échoit à David, le dévoilement progressif et partiel, sous les figures du miracle et de la fable, de la rénovation des temps et du monde par le Christ revient à Protée. ${ }^{10}$

${ }^{9}$ PARENTI, 1985, p. 9 s., com indicações dos textos com ocorrência dessa comparação.

${ }^{10}$ DERAMAIX, p. 95 s. 
Apesar de Proteu se concentrar nas coisas humanas, Sannazaro foi criticado entre outros por Erasmo de Roterdão pelo uso de uma divindade pagã como profeta de Jesus Cristo. O próprio Sannazaro tinha antecipado essa crítica e justificou o seu uso de Proteu numa carta. ${ }^{11}$ Por conseguinte, o tradutor quinhentista do De partu virginis eliminou a figura de Proteu na sua versão em língua italiana e substituiu-o por Isaías. ${ }^{12}$

A segunda recriação sannazaresca do mito de Proteu encontra-se na coleção de éclogas de pescadores, as Eclogae piscatoriae, e de modo semelhante também na canção XI dos Rime. Nesta última, o locutor do poema atribui ao domínio de Federico III em Nápoles o poder de submeter Fortuna e de agraciar de paz e calma até os deuses marinhos. É assim que Proteu renuncia às suas transformações e vaticina a verdade a qualquer pessoa que lhe colocar uma pergunta:

[...] Protèo, ben che si pòsi o dorma, più non si cangia di sua propria forma,

${ }^{11}$ A carta é dirigida a Antonio Seripando e data do dia 13 de abril de 1521. O argumento principal a favor de Proteu é a necessidade de variatio entre as profecias no De partu virginis: "La medesma cagione mi indusse a non fare che'l profeta due volte parlasse, per diverso che fusse, che al parer mio saria stato una povertà di ingegno e cosa tutta contraria a l'intento mio, che non penso in altro tanto, quanto in non dare fastidio a chi lege". Acrescenta-se a ideia de que Deus deve ter querido ser anunciado por todos ("tengo che Dio volse essere bandito da tutto il mondo"). Finalmente Sannazaro lembra que no De partu virginis diz-se de maneira conforme à religião que Proteu mente noutros assuntos, mas diz verdade neste caso. SANNAZARO, 1961, p. 372 s.

${ }^{12}$ A ed. de Stefano Prandi (SANNAZARO, 2001) oferece as duas versões do poema. - Cf. também os comentários sobre a figura de Proteu em De partu virginis em QUINT, 1983, p. 76-78. 
ma in su gli scogli assiso, ove ei s'asconde, chiaramente risponde

a chi il dimanda, senza laccio o nodo, e de' tuoi fati parla in cotal modo: $[\ldots]^{13}$

Após o louvor do monarca referido pelo mesmo Proteu em estilo direto, ele afunda-se bruscamente nas ondas, do modo conhecido: "E così detto, tacque, / e lieve e presto si gettò ne l'acque". ${ }^{14}$

Na quarta das Eclogae piscatoriae, sob o título Proteus, também é o próprio deus que vaticina as circunstâncias dolorosas da perdição da dinastia aragonesa no Sul da Itália e do exílio do próprio Sannazaro. O poema é dedicado a Fernando de Aragão, Duque de Calábria e filho de Federico III. Em primeiro lugar, o narrador da écloga invoca as ninfas da baía de Nápoles e o Duque, seu patrão. A seguir, relata como dois pescadores teriam escutado Proteu a cantar de noite pastoreando as suas focas:

Illum olim veteris pascentem ad saxa Minervae mulcentemque suas divino carmine phocas e puppi sensere Melanthius et Phrasidamus, ut forte a Capreis obscura nocte redibant. ${ }^{15}$

Proteu cantaria alegremente tais palavras que os mortais não seriam capazes de referir: "Ipse autem haudquaquam mortali digna referri / verba sono vacuas laetus cantabat ad auras" (v. 28 s.). Quase exclusivamente em estilo indireto, é referido a seguir o canto de Proteu sobre vários episódios da história mítica antiga da região de Nápoles. Depois, o canto

\footnotetext{
13 SANNAZARO, 1961, p. 143.

14 SANNAZARO, 2009, p. 128.

${ }^{15}$ SANNAZARO, 1961, p. 145.
} 
abrange até o surgimento de Melisaeus (o pseudônimo bucólico de Giovanni Pontano) e os seus poemas astronômicos (Urania e Meteora), e termina num catálogo dos reis napolitanos e as batalhas deles, as quais porém o narrador resume em dois versos. Finalmente, Proteu relata como uma sorte ingrata levou Fernando para além dos Alpes nas margens do Loire (onde efetivamente o Fernando real faleceu exilado no ano de 1504).

Em Sannazaro a figura de Proteu está centrada num único domínio, a história humana - mesmo no contexto sacro do De partu virginis - e é desenvolvida a sua associação com o mundo bucólico dos pastores. Finalmente, Sannazaro aumenta a carga metapoética da figura na Écloga Proteus, onde o deus aparece pela primeira vez como poeta e cantor.

\subsection{Ariosto}

O segundo modelo de uma recriação narrativa do mito protéico encontra-se no Orlando furioso, de Ariosto (VIII, 51-58). Trata-se do episódio da ilha Ebuda nas proximidades da Irlanda. Essa ilha é infestada e assolada pelos monstros marinhos que Proteu teria mandado por vingança - desde então tem-lhe sido sacrificadas regularmente as mais belas virgens. $\mathrm{O}$ ritual cruel teria a sua origem numa história cuja verossimilhança é sujeita a dúvidas pelo próprio narrador: Proteu teria engravidado a filha do rei da ilha, e o pai teria matado a descendência do deus antes de nascer. Então Proteu, quebrando toda lei, teria mandado os seus monstros marinhos à terra para destruirem o gado, as vilas e os seus moradores:

Proteo marin, che pasce il fiero armento di Nettuno che l'onda tutta regge, sente de la sua donna aspro tormento, e per grand'ira, rompe ordine e legge; sì che a mandare in terra non è lento 
l'orche e le foche, e tutto il marin gregge, che distruggon non sol pecore e buoi, ma ville e borghi e li cultori suoi. ${ }^{16}$

Essa devastação teria continuado até um oráculo vaticinar que virgens iam ter que ser sacrificadas até Proteu se satisfazer com uma delas. Desde então em Ebuda seria sacrificada diariamente uma virgem aos seres oceânicos - uma sorte que na continuação deste famoso episódio, Angélica corre perigo de incorrer.

O sacrifício das virgens ocasionado pelo oráculo faz com que a vingança de Proteu apareça como motivada por motivos libidinosos, ao passo que são descartados outros possíveis motivos, como, p. ex., o orgulho paternal ferido pela criança não nascida. Proteu aparece aqui, na sua ira irrefreável e sua vingança descomedida que dá motivo ao sacrifício cruel, como apaixonado monstruoso excessivo no limiar do ensandecimento e como destruidor da civilização.

As duas recriações renascentistas italianas do mito protéico de Sannazaro e Ariosto escolhem caminhos bem diferentes, mas vão unidas na caraterística de descartarem as autotransformações do deus marinho que na Antiguidade e em Pico della Mirandola tinham sido centrais.

Resumindo esse panorama da figura de Proteu constatase que nos principais exemplos da Antiguidade ele caracterizase pela sua capacidade de autotransformação contínua e o saber abrangente, incluindo a profecia. A proximidade dessas caraterísticas com temas metapoéticos é usada, em Nonnos para associar Proteu e o poeta, sem porém converter o deus mesmo na figura dum poeta. Nessa linha da variabilidade no primeiro lugar situa-se também a primeira referência renascentista a Proteu em Pico della Mirandola que usa o deus para compará-

${ }^{16}$ ARIOSTO, 1976, estr. 160. 
lo com o homem. No entanto, as duas recriações narrativas do mito protéico em Sannazaro e Ariosto descartam o motivo da autotransformação. Sannazaro recorre no lugar dele à fala profética do deus e torna-o num profeta das coisas humanas em contextos diferentes. No De partu virginis a sua profecia é proferida indiretamente, e na canção e na écloga é Proteu mesmo que fala ou então já canta: a écloga Proteus parece marcar a etapa para chegar numa figura de Proteu-poeta e cantor. Ariosto, no entanto, molda Proteu como um monstro amador excessivo e destruidor da civilização.

\section{Proteu na poesia épica renascentista portuguesa}

\subsection{Luís de Camões: Os Lusíadas}

Proteu fará a sua primeira aparição na épica portuguesa n'Os Lusíadas. É conhecido como no regresso da sua viagem para a Índia, Vasco da Gama e os seus homens, antes de chegarem a Lisboa, topam com uma ilha fabricada para eles por Vênus, e povoada de ninfas à espera dos marinheiros. É nesse episódio da chamada 'Ilha dos Amores' - se calhar o episódio mais comentado da literatura portuguesa antiga - que os dois mundos da ficção narrativa se encontram: até esse episódio, o mundo dos homens e o mundo dos deuses tinhamse mantido separados. A figura de Vasco da Gama nunca, ao longo do poema, entra em contato direto com os deuses que determinam o percurso da sua viagem. Esse contato acontece só quando os marinheiros pisam a ilha mitológica. É aqui que o mundo humano da experiência encontra o mundo da mitologia dos deuses pagãos - e mitologia pagã, no contexto do séc. XVI, não significa transcendência, mas sim um mundo de ficção poética. A mitologia greco-romana, no séc. XVI, é a ficção poética por excelência, e até a antonomásia dela. Tendo presente essa ideia é como se explica melhor o que acontece a 
seguir na Ilha dos Amores. Os marinheiros ficam envolvidos em cenas de grande erotismo com as ninfas; mas salienta-se entre essas cenas aquela de Lionardo, um marinheiro ao percalço da 'sua' ninfa Efire. Ele não apanha o objeto do seu desejo pela força, como os seus companheiros, mas consegue os favores da ninfa com a ajuda de um canto lírico, queixandose da sua má sorte amorosa. Efire ouve o canto de quem vai atrás dela, e rende-se ao amor. Eis o que se pode chamar uma 'encenação narrativa' da poesia lírica e dos seus efeitos.

Mas a Ilha dos Amores reserva mais para os marinheiros e os leitores à procura de deleite: na segunda parte do episódio, os marinheiros descansam no banquete oferecido a eles no palácio de Tétis. Aqui dá-se a segunda encenação da poesia que desta vez diz respeito à poesia épica. No banquete, uma ninfa sem nome, acompanhada de música, canta profeticamente os feitos dos vice-reis portugueses na Índia. Encena-se, portanto, a recitação musicada de uma micro-epopeia dentro da epopeia camoniana. ${ }^{17}$ Vejamos de novo essa cena no início do canto $\mathrm{X}$ :

$[\ldots]$

Músicos instrumentos não faltavam

(Quais, no profundo Reino, os nus espritos

Fizeram descansar da eterna pena)

Cûa voz dûa angélica Sirena.

Cantava a bela Ninfa, e cos acentos, Que pelos altos paços vão soando, Em consonância igual, os instrumentos Suaves vêm a um tempo conformando. Um súbito silêncio enfreia os ventos $\mathrm{E}$ faz ir docemente murmurando

${ }^{17}$ A encenção da poesia neste episódio camoniano, focando sobretudo nos efeitos dela, é analisada em comparação com Garcilaso de la Vega em FRIEDLEIN, 2008. 
As águas, e nas casas naturais Adormecer os brutos animais.

Com doce voz está subindo ao Céu Altos varões que estão por vir ao mundo, Cujas claras Ideias viu Proteu Num globo vão, diáfano, rotundo, Que Júpiter em dom lho concedeu Em sonhos, e despois no Reino fundo, Vaticinando, o disse, e na memória Recolheu logo a Ninfa a clara história.

Matéria é de coturno, e não de soco, A que a Ninfa aprendeu no imenso lago; Qual Iopas não soube, ou Demodoco, Entre os Feaces um, outro em Cartago. ${ }^{18}$

A recitação da ninfa produz efeitos órficos, a natureza animada e inanimada rendendo-se a ela. Que ela seja épica e do registro alto, não há lugar de dúvida: os feitos dos "altos varões" são "matéria de coturno". Com diferença dos dois modelos desta cena existentes na tradição épica, a ninfa camoniana, qual uma sereia, toma conta apenas dos aspectos performáticos da recitação. Nos banquetes da Odisseia e da Eneida, os cantores Demodoco e Iopas foram responsáveis pelo conteúdo e pela forma musicada. Aqui no entanto, os feitos cantados têm uma fonte precisa. A ninfa lembra-se dos ditos que ela ouvira da boca profética de Proteu no fundo do mar, e ele os soubera num sonho em que Júpiter lhos deixara ver numa bola de cristal ("globo vão, diáfano, rotundo"). Na encenação da poesia da Ilha dos Amores, Proteu é portanto envolvido no processo poético como quem transmite e garante a validade dos conteúdos da poesia épica. Proteu de um lado, na sua característica de vaticinador, fica responsável pelo

${ }^{18}$ CAMÕES, 1987, ESTR. 5-8. 
conteúdo profético (que em clave retórica, é a inventio) e a ninfa do outro lado, responsável pela forma poética e a atuação cantada (dispositio e gestus). Camões segue, portanto, o modelo de Sannazaro no De partu virginis, escolhendo a face profética da figura de Proteu, e faz o mito evoluir para um mito metapoético em que o deus marinho cumpre uma função específica, mas parcial, no processo poético.

Nesta altura impõe-se a necessidade de um esclarecimento terminológico. Werner Wolf publicou recentemente uma proposta terminológica que visa a cobrir o conjunto de fenômenos relacionados à autorreferencialidade dos textos literários. ${ }^{19}$ Seguindo o seu esquema, em primeiro lugar, falar-se-á de autorreferencialidade quando um texto não faz referência ao mundo real externo, nem tão-pouco a outros textos, e sim a "elementos ou aspetos da própria obra, do seu gênero textual ou da sua midialidade ${ }^{\prime 20}$ (alterorreferencial vs. autorreferencial). Um exemplo de simples autorreferencialidade seria, nesta proposta, o fenômeno da rima: a segunda parte duma rima remete para a primeira. Este tipo de autorreferen-cialidade não implica nenhuma constituição de sentido, a rima sendo, por assim dizer, 'referência pura'. No entanto, uma autorreferencialidade que tem sim caráter proposicional e formula reflexões sobre algum elemento do texto nomear-se-ia autorreflexividade. Disso seria questão, por exemplo, num comentário do narrador sobre algum dos seus personagens, tratando-o como se de um ser vivo se tratasse. Nesse caso, a voz do narrador não se eleva para cima do mundo da ficção. Ora, num terceiro passo, distingue-se

${ }^{19}$ Cf. o artigo do anglicanista da Universidade de Graz (Áustria) intitulado "A metaização como fenômeno transgenérico e transmedial. Uma proposta de sistematização de formas e conceitos metarreferenciais na literatura e outras mídias". WOLF, 2007.

${ }^{20}$ WOLF, 2007, p. 31. 
desse tipo de autorreflexividade aquela outra que manifesta ter consciência do sistema em que se encontra, como é o mundo ficcional, e se eleva, essa sim, por cima dele. É para esses casos que Werner Wolf reserva o termo de metarreferência ou metarreflexividade, como são os comentários do narrador, por exemplo, sobre a própria obra, a sua estrutura, o seu caráter ficcional, o seu gênero, ou sobre a poesia, a literatura ou outras mídias no geral. De metarreflexividade interna, pode-se falar quando as reflexões dizem respeito especificamente à obra em que se encontram (aquilo que com André Gide viemos a chamar uma mise-en-abyme), e de metar-reflexividade externa, quando as reflexões visam o gênero ou a mídia em que nos encontramos.

No caso da Ilha dos Amores, fazem-se obviamente proposições não sobre Os Lusíadas próprios, mas sobre a constituição da poesia no geral. Sem chegar à exibição metarreflexiva conhecida das metalepses de Ariosto, n'Os Lusíadas é mais a própria ação do episódio da Ilha que transmite essas reflexões. Contudo, as personagens deixam, por vezes, aflorar consciência metarreflexiva, como quando Tétis afirma que ela e suas companheiras não são mais do que seres de ficção:

\section{[...] eu, Saturno e Jano,}

Júpiter, Juno, fomos fabulosos,

Fingidos de mortal e cego engano. ${ }^{21}$

Quais são concretamente as afirmações metarreflexivas que n'Os Lusíadas se fazem sobre a poesia? O episódio da Ilha dos Amores encena numa ordem ascendente a lírica amorosa, a poesia épica, e no final, uma forma superior de conhecimento, ${ }^{22}$ quando Vasco da Gama, na terceira e última fase do episódio, contempla com Tétis o modelo do mundo. Uma das proposições

${ }^{21}$ CAMÕES, 1987, CX, estr. 82.

${ }^{22}$ AGUIAR E SILVA, 1994, p. 141. 
básicas implícitas seria, portanto, que a poesia amorosa se situa num nível mais baixo e sensualizado que a épica, e essa, por sua vez, abaixo da constituição do saber. Nessa encenação, Proteu atua como quem garante a veracidade da poesia épica. Ele representa a verdade empírico-histórica latente por baixo da forma artística do canto épico.

\subsection{Jerónimo de Corte-Real: Naufrágio de Sepúlveda}

A Jerónimo de Corte-Real, autor de três poemas épicos e coetâneo de Camões, ${ }^{23}$ deve-se a segunda plasmação épica de Proteu. O seu Naufrágio de Sepúlveda, editado postumamente no ano 1594 em Lisboa, poderia ser considerado em vários aspectos um 'Anti-Lusíadas', já que esse poema canta o fracasso de uma viagem marítima:

- quando em Camões há profecia do império português, em Corte-Real há profecia da derrota fatal de D. Sebastião,

- quando em Camões a viagem leva os protagonistas à apoteose na ilha mitológica, em Corte-Real leva-os à morte depois dum naufrágio na costa de Moçambique e à subida para a glória no céu.

- e quando em Camões, o objetivo da viagem é a entrada dos protagonistas no mundo da poesia, em Corte-Real a poesia é também presente e encenada, mas com uma função radicalmente diferente. ${ }^{24}$

${ }^{23}$ Cf. o percurso biobibliográfico construído pela própria obra de Corte-Real em ALVES, 2005. Os dados biográficos propriamente despreendem-se da introdução às obras de Corte-Real por M. Lopes de Almeida (CORTE REAL, 1979).

${ }^{24}$ Uma análise comparativa mais demorada e focada na valoração diferente do saber humano nas duas epopeias encontra-se em FRIEDLEIN, 2007. 
Já o título Naufrágio e Lastimoso Sucesso da Perdiçam de Manuel de Sousa de Sepúlveda e Dona Lianor de Sá sua molher efilhos vindo da India [...] salienta a sorte desastrosa dos dois protagonistas, Manuel de Sepúlveda e Lianor de Sá. ${ }^{25}$ No seu conjunto, o poema pode ser entendido como a narração de um amor fatídico que começa com um crime passional, e a expiação desse crime pelo casal Manuel e Lianor, ambos encontrando a morte depois do naufrágio e após uma longa deambulação pelas terras desérticas da costa africana. Já perto de morrer, Manuel de Sepúlveda experiencia a visão sonhada de um Templo da Verdade, e é esse conhecimento que apesar da sua culpa justifica a sua ascensão para a glória após a morte. $\mathrm{O}$ poema baseia-se, portanto, numa sequência "pecado - expiação - conhecimento - graça divina". Nesta estrutura de base, o amor terreno e sensual tem um elevado valor negativo que é demonstrado no percurso vital de Manuel de Sepúlveda e sua mulher, mas sobretudo em três innamoramenti sucessivos. Eles são experimentados pelos deuses Proteu, Pã e Apolo. Todos eles apaixonam-se por Lianor deSá por causa da sua descomunal beleza. O primeiro caso é Proteu. Na travessia da cidade de Goa para África, Lianor, com os marinheiros, observa Proteu desde a nau a surgir do mar como um peixe gigantesco:

O velho Protheo vio, que em duas asas

Espinhosas, \& grandes se sustenta [...]

Olha o peito escamoso, a cor, \& o rosto

A proporção, \& o talho differente

Olha aquella figura estranha aos homēs

Mas conhecida \& vsada á natureza. ${ }^{26}$

${ }^{25}$ Cf. o resumo do texto em ALVES, 2001, p. 233-240, acompanhado de uma análise centrada na função do maravilhoso.

${ }^{26}$ CORTE REAL, 1979, Nau VI, p. 600. 
O sofrimento do velho Proteu, subitamente acometido de amor pela bela Lianor culmina num monólogo de lamentação e no colapso dele diante do trono de Netuno:

O sabio velho cae desfigurado

Ante os pès de Neptuno, \& fica o triste

Cuberto de hum suor copioso, \& os olhos

Irtos, sem mouimento, \& sem luz viua.

O coração aflicto pulsa, \& bate

Que parece romperlhe o frio peito,

Hum açodado hanellito, euidente

E clara mostra a intrinseca agonia. ${ }^{27}$

Os sintomas físicos dessa cena bizarra fazem o velho Proteu virar uma figura grotesca, atingida por uma catalepsia: o vidente sábio torna-se um vulto sem dignidade que provoca a compaixão dos circunstantes.

Com cega, densa, turua, escura vista

Mostra hũa fera image, mostra em tudo

Espantosa, mortal, triste figura. ${ }^{28}$

Proteu perde a sua sabedoria, dignidade e capacidade de percepção do mundo externo, como quem é iludido por um sonho vão.

O graue varão sabio, ja não sabio,

Ia não graue se assenta mudo \& triste,

Nada ouue do que dizem, nada entende

Tão transportado estaua em seus amores. [...]

Como aquelle que entregue a hũ doce sono

Onde apparencias vaãs, \& ledas formas

De fantasticos bēs se representão.

${ }^{27}$ CORTE REAL, 1979, Nau VI, p. 603.

${ }^{28}$ CORTE REAL, 1979, Nau VI, p. 604. 
Com aluoroços falsos \& fingidos

Estando assi enganado està contente

Isenta de tristezas a memoria

Suspenso fica \& triste quando abertos

Os olhos, da ficção se desengana. ${ }^{29}$

Na canção lírica que posteriormente Proteu recita para as ninfas que lhe acompanham, ele reconhece o caráter vão da sua fúria amorosa, e o paradoxo de estar a desejar o amor como remédio para o seu sofrimento.

Neste misero estado trabalhoso

Busco para remedio hum falso engano,

O qual despois me deixa quebrantado,

Que em fim cansa o vão gosto imaginado. ${ }^{30}$

Mas Proteu não é o único apaixonado pela bela Lianor. Quando ela pisa terras africanas depois do naufrágio, num cenário bucólico, será o deus Pã que se apaixona por ela, e também ele, cantando, oferece-lhe as riquezas da sua vida campestre. Por terceiro, depois da andança interminável dos náufragos pelo país, e poucos momentos antes da sua morte num deserto de areias ardentes, será Apolo que descobrirá a bela e nua Lianor, e que, acometido de amor por ela, descerá da quarta esfera para a terra e cantar-lhe-á, ardendo nas suas chamas, uma única canção amorosa.

Apolo no fogo do sol e do deserto, Pã na terra, Proteu nas águas - e antes deles havia surgido o deus Amor voando pelo ar até o lugar do crime passional: cada um dos deuses apaixonados por Lianor é associado com um dos quatro elementos. Mas além disso, cada um deles relaciona-se com um dos quatro tipos humorais da medicina coetânea: de Amor diz-se que é colérico, Pã

${ }^{29}$ CORTE REAL, 1979, Nau XIV, p. 811.

${ }^{30}$ CORTE REAL, 1979, Nau XIV, p. 815. 
demonstra o comportamento do amante fleumático, Apolo exemplifica o amor sanguíneo - e Proteu, que é constantemente acompanhado do adjetivo triste, representa o humor melancólico. Por conseguinte, ele tem a tendência de se evadir da companhia dos outros deuses marinhos para deleitar-se no seu 'suave mal', e ele demonstra o comportamento típico do melancólico, inconstante e maníaco-depressivo:

A triste, fraca presa, ja sogeita

Ao nociuo veneno, \& licor frio:

Ora braua com furia, ora rendida

Humilde por seu mal, \& entregue à morte. ${ }^{31}$

Os efeitos do amor no velho Proteu são, portanto, sobretudo dois - em primeiro lugar, longe do amor neoplatônico que conduziria ao conhecimento, o amor de Proteu faz-lhe perder as suas capacidades de sabedor e vidente, e deixa-lhe impedido por um amor terreno, elemental, paralisador e sem esperança. Em segundo lugar, porém, há que se salientar como as poesias compostas por esse apaixonado melancólico têm certo sucesso que se produz não na destinatária direta delas, e sim no público geral: as canções amorosas protéicas são cantadas pelas ninfas marinhas, e o público de deuses oceânicos fica preso e quase pasmado, acometido de pena do amante sofredor. Proteu como poeta melancólico no Naufrágio de Sepúlveda, é ao mesmo tempo a imagem do poeta de sucesso.

A poesia encenada através dos deuses e os seus cantos de amor no Naufrágio de Sepúlveda é uma poesia lírica com finalidades sensuais proferida pelos deuses do paganismo. Afinal de contas, a bela Lianor ficará incomovível face a esses cantos, resistirá a qualquer tentação sensual e, virtuosa, subirá ao céu. Não obstante essa visão da poesia que a priori poderia parecer

${ }^{31}$ CORTE REAL, 1979, Nau VI, p. 600. 
negativa, ela consegue remanescer e subsistir no âmbito terreno que é próprio dela: o Naufrágio de Sepúlveda termina numa cena em que o velho Proteu e os outros deuses rejeitados, agora reunidos por volta da sepultura de Lianor, deixam epitáfios poéticos para a bela morta.

No Proteu de Corte Real, desenvolve-se a linha da personagem libidinosa e monstruosa, submetida às suas paixões, começada por Boccaccio e Ariosto. Corte Real introduz, porém, o elemento inovador da melancolia de Proteu que propicia e impregna a sua atividade poética. É sabido que o temperamento melancólico, condicionado pela bílis negra, desde Aristóteles e os Problemata está associado, entre outros, aos filósofos, artistas e poetas:

Now black bile, which is naturally cold and does not reside on the surface when it is in the condition described, if it is in excessive quantity in the body, produces apoplexy or torpor, or despondency or fear; but if it becomes overheated, it produces cheerfulness with song, and madness, and the breaking out of sores and so forth. ${ }^{32}$

Com o seu entorpecimento apoplético, seguido pela produção de cantos amorosos, o Proteu de Corte Real conformase à diagnose aristotélica. Corte Real associa, portanto, o motivo de Proteu libidinoso e passional ariostesco com a melancolia de origem aristotélica, propensa à sensualidade e ao mesmo tempo à criação artística. Tornado num poeta deste tipo, o Proteu da literatura épica portuguesa evolui para um mito com maiores traços metarreferenciais. A imagem da poesia à qual esse mito contribui, tanto no Naufrágio de Sepúlveda quanto n'Os Lusíadas, é a de uma empresa exclusivamente terrena e profana. Mas no Naufrágio de Sepúlveda, ela carece dos

32 ARISTÓTELES, 1957, p. 160-163. 
poderes ilocutórios que demonstram os cantos de Lionardo e da ninfa na Ilha dos Amores. Eles conseguem os seus objetivos erótico e glorificador, enquanto os cantos no Naufrágio de Sepúlveda apenas conseguem imortalizar Lianor sem, no entanto, fazer realidade os desejos eróticos dos deuses poetas. Essa frustração marca a poesia encenada na epopeia de Corte Real. Ela recebe a tonalidade pessimista do texto inteiro, e a figura de Proteu fica tingida da mesma cor.

\subsection{Bento Teixeira: Prosopopeia}

A Prosopopeia (1601) de Bento Teixeira costuma ser apreciada na sua importância como o primeiro poema épico do Brasil em língua portuguesa, e como o primeiro texto literário do Brasil que chegou a ser impresso: por vezes, coloca-se por conta disso como início da história literária brasileira. Além do mais, é a biografia trágica do autor, morto no cárcere da Inquisição em Lisboa, que desperta um merecido interesse. ${ }^{33}$ Aqui, no entanto, vamos focar no próprio poema, que é onde a figura de Proteu recebe a sua plasmação mais abrangente na literatura lusófona do Renascimento. ${ }^{34} \mathrm{O}$ poema consta de um único

${ }^{33}$ Bento Teixeira nasceu como filho de cristãos-novos em 1561, no Porto, e mudou-se já em idade de criança para o Espírito Santo, e mais tarde para o Rio de Janeiro, Bahia e Olinda. É vítima de um julgamento do tribunal da Inquisição por causa de blasfêmia. Suspeito de judaísmo, é transferido para Lisboa em 1596, onde abjura num auto-de-fé em 1599, mas falece no cárcere pouco depois, em 1600. Cf., também acerca da bibliografia sobre Bento Teixeira, o estudo de COSTIGAN, 2003, extensamente documentado no que diz respeito ao contexto cripto-judaico.

${ }^{34}$ Não fazemos questão de discutir a pertinência epocal do poema de Bento Teixeira que às vezes foi considerado a primeira mostra de poesia barroca no Brasil. 
canto de 94 oitavas e é acompanhado de uma carta para Jorge de Albuquerque, governador da capitania pernambucana, e um soneto final dirigido a ele mesmo. Da carta dedicatória, despreende-se que o poema teria sido concebido como rascunho para uma obra maior, uma vez que essa for autorizada pelo destinatário. Mesmo assim, pode-se afirmar que o poema possui unidade e acabamento, e assemelha-se no seu corte a um modelo que vamos discutir a seguir.

Lembramos que a Prosopopeia começa por um proêmio épico, constituído pela propositio de cantar os feitos do governador Jorge de Albuquerque, a invocatio de Deus (em lugar das musas) e a dedicatio ao mesmo patrão. A esse começo-padrão de poema épico, segue-se a narratio a partir da sétima estrofe. Nela é plasmada uma cena marinha noturna em que Tritão surge das águas para anunciar a chegada de Netuno, em carro triunfal, e o seu cortejo de deuses marinhos, ninfas e sereias. Entre eles, o velho Proteu é apresentado como vaticinador da sorte humana, e como quem se vê ameaçado para não abusar da sua capacidade de autotransformação:

Vem o velho Proteu, que vaticina

(Se fé damos à velha Antigüidade)

Os males a que a sorte nos destina,

Nascidos da mortal temeridade.

Vem numa e noutra forma peregrina,

Mudando a natural propiedade.

Não troque a forma, venha confiado,

Se não que de Aristeu ser sojigado. ${ }^{35}$

O conjunto do cortejo de divindades deita-se numa lage perto do recife da capital pernambucana. É essa descrição do Recife $^{36}$ que despertou mais interesse em quem busca marcas

35 TEIXEIRA, 2008, estr. XV.

36 TEIXEIRA, 2008, estr. XVII-XX. 
de brasilidade na literatura antiga. Nesse noturno pernambucano Proteu vai entoar o seu canto, introduzido por sua vez, por um proêmio épico próprio que se insere na tradição ibérica da 'poética da verdade':

De lanças e d'escudos encantados

Não tratarei em numerosa rima,

Mais de barões ilustres afamados,

Mais que quantos a musa não sublima.

[...] dado que a forma se me muda,

Em falar a verdade serei raso. ${ }^{37}$

Esta 'verdade' de Proteu será profética, de modo que toda a parte central da Prosopopeia fica essencialmente no tempo verbal do futuro. Os feitos de Jorge de Albuquerque resumemse sobretudo na travessia do Atlântico a caminho de Lisboa, e na sua participação na expedição militar de D. Sebastião no Norte da África. Enquanto o irmão de Jorge, Duarte de Albuquerque, morre na batalha, Jorge é preso e será resgatado só depois. No relato épico de Proteu, o deus Vulcão tentará impedir a travessia do Atlântico mandando uma tempestade (discurso de Vulcão). ${ }^{38}$ Nessa situação de perigo, Jorge saberá brilhar com as suas capacidades oratórias num discurso aos marujos apavorados, ${ }^{39}$ e a nave conseguirá sair desse transe. Do mesmo modo, ainda que com menos sucesso, salienta-se oratoriamente na batalha de Alcácer-Quebir em que dirige um discurso a El-Rei D. Sebastião ${ }^{40}$ e aos seus companheiros de combate em plena fuga. ${ }^{41}$ No relato de Proteu, a cidade de Olinda afunda após a batalha perdida

\footnotetext{
37 TEIXEIRA, 2008, estr. XXIII s.

38 TEIXEIRA, 2008, estr. XLVII-LIII.

39 TEIXEIRA, 2008, estr. LVIII-LXVI.

40 TEIXEIRA, 2008, estr. LXXVI s.

${ }^{41}$ TEIXEIRA, 2008, estr. LXXXIII-LXXXVI.
} 
numa profunda dor pela morte de Duarte de Albuquerque. É aqui que Proteu encerra o canto para o seu patrão Netuno. Esse mostra-se convencido de que Albuquerque merece doravante ser venerado com cantos, e após essas breves palavras o narrador afirma ter presenciado o regresso do cortejo marinho às profundezas do mar de Pernambuco.

Seria difícil não perceber as semelhanças entre esse canto de Proteu na costa pernambucana, da pena de Bento Teixeira, e o canto protéico na costa napolitana da écloga Proteu de Sannazaro, uma vez que identificamos essa poesia como modelo para o poeta brasileiro. Os paralelos ficam mais salientes tendo em conta a variedade de plasmações que na altura a figura de Proteu já pôde assumir: Teixeira escolhe com Sannazaro um cenário noturno (quando na Antiguidade é expressamente no meio-dia que Proteu há de se prender), e descreve um deus vaticinador, cantor de uma história profana estreitamente ligada ao padrão do poema respectivo, e baseada numa historicidade garantida que exige congelar a capacidade transformatória do deus marinho. Bento Teixeira desenvolve o modelo da écloga sannazariana no sentido de um tom marcadamente mais épico, mas deixa a realização de um poema de dimensões realmente épicas para um futuro anunciado na dedicatória e, novamente, no final do canto de Proteu. Não há dúvida de que o Proteu de Teixeira é projetado para ser a figura dum poeta e cantor épico num poema que não passa de uma epopeia in nuce.

Tendo em conta as dimensões reduzidas do poema, salienta-se no canto épico de Proteu quanto espaço fica nele reservado para as digressões metarreflexivas: ao proêmio épico de quatro oitavas ${ }^{42}$ acrescenta-se em primeiro lugar um enxerto metarreflexivo do narrador acerca da personagem de Jerónimo

TEIXEIRA, 2008, estr. XXII-XXV. 
de Albuquerque. ${ }^{43}$ Logo depois seguem reflexões relativas à ordem da matéria narrada ${ }^{44} \mathrm{e}$ um lamento acerca do conservadorismo do público que não está nem disposto nem capaz de ouvir coisas que são novidade, mesmo sendo verídicas: ${ }^{45}$

Uma cousa me faz dificuldade E o esprito profético me cansa, A qual é ter no vulgo autoridade, Só aquilo a que sua força alcança.

Mas se é um caso raro, ou novidade

Das que, de tempo em tempo, o tempo lança,

Tal crédito lhe dão, que me lastima,

Ver a verdade, o pouco que se estima. ${ }^{46}$

Também não faltam passagens sobre a problemática que se dá quando os feitos de Albuquerque superam os modelos antigos homérico e virgiliano. ${ }^{47} \mathrm{~A}$ isso acrescenta-se um trecho relativo à dispositio do relato, em que o narrador épico se chama a ele próprio para a ordem e de volta para o que é o tema propriamente, ${ }^{48}$ assim como o final do canto protéico, ${ }^{49} \mathrm{em}$ que o narrador se apresta para uma vindoura continuação do seu canto:

Não mais, esprito meu, que estou cansado,

Deste difuso, largo, e triste canto,

Que o mais será de mim depois cantado

Por tal modo, que cause ao mundo espanto. ${ }^{50}$

\footnotetext{
${ }^{43}$ TEIXEIRA, 2008, estr. XXXIII.

${ }^{44}$ TEIXEIRA, 2008, estr. XXXIX.

${ }^{45}$ TEIXEIRA, 2008, estr. XL s.

${ }^{46}$ TEIXEIRA, 2008, estr. XLI.

${ }^{47}$ TEIXEIRA, 2008, estr. XLII s.

${ }^{48}$ TEIXEIRA, 2008, estr. LXXXI s.

${ }^{49}$ TEIXEIRA, 2008, estr. XLII.

${ }^{50}$ TEIXEIRA, 2008, estr. LXXV.
} 
Aliás, a metarreflexividade encontra-se em todos os níveis pragmáticos do poema, e não só no narrador Proteu. O narrador primário também reflete sobre seu poema, como quando ele apresenta Tritão comparando-o com o Tritão d'Os Lusíadas:

Vinha Tritão em cola duplicada,

Não lhe vi na cabeça casca posta,

(Como Camões descreve) de lagosta. ${ }^{51}$

Mas até o locutor terciário Albuquerque, dentro do canto de Proteu, orna os seus discursos de reflexões metarreflexivas quando pensa na narrativa vindoura que os seus companheiros poderão fazer uma vez superados os transes de tempestades e batalhas. ${ }^{52}$ A princípio esses tipos de incursões metarreflexivas não significam nada invulgar para um narrador épico. Mais ainda do que Os Lusíadas, o narrador do Orlando furioso é conhecido por esse tipo de metalepse, e outras ainda mais espetaculares.

Ora, o Proteu de Teixeira incorpora ao mesmo tempo o vates e o poeta. Essa dualidade parece apontar para o conceito neoplatônico do poeta inspirado divinamente. Será portanto que quem fala aqui é um poeta vates, oposto ao poeta doctus que tira a sua poesia da erudição? Dado que o Proteu aqui encenado é vates e poeta, ele porém não é atingido pelo furor poético. A matéria do seu canto vem-lhe dada desde 'cima' ("Proteu, no céu cos olhos enlevados, / Como que investigava alto secreto, $\left.[\ldots]^{\prime \prime}\right),{ }^{53}$ mas na prática poética, em vez de ficar preso como instrumento cego pelo furor emanente de uma potência superior, Proteu mostra-se como narrador autônomo e metarreflexivo que nunca deixa de ser senhor do seu relato. Na recitação ele

${ }^{51}$ TEIXEIRA, 2008, estr. $X$.

52 TEIXEIRA, 2008, estr. LXXXIV.

${ }^{53}$ TEIXEIRA, 2008, estr. XXXI. 
aparece na pose do orador, com "voz bem entoada e bom meneio" ${ }^{54}$ Em certo momento, ele para o seu canto,

E com nova eficácia começando

A soltar a voz alta e vigorosa,

Estas palavras tais tira do peito,

Que é cofre de profético conceito. ${ }^{55}$

"Eficácia", "voz alta e vigorosa" e "tirar palavras do peito" caracterizam mais um orador erudito do que um objeto de furor cego. Esse conceito de poesia orientada para a retórica reflete-se também no fato de que no canto épico de Proteu, os elementos mais salientes são precisamente os discursos, proferidos por Vulcão e Jorge de Albuquerque. A atividade de um Proteu oratoriamente habilidoso e metarreflexivo gera uma poesia que, aqui também, é uma empresa terrena e política, voltada para a criação da fama, e de valor positivo sem restrições. $\mathrm{O}$ poeta dela não obedece a potências transcendentais, e sim a uma instância política do seu próprio mundo - seja essa o patrão Jorge de Albuquerque para o narrador primário, ou seja Netuno para o narrador Proteu. O poeta Proteu reflete a situação do poeta Teixeira: "Proteus poeta alter".

Colocando a Prosopopeia não no contexto do seu modelo italiano, mas no da poesia épica da sua própria língua, evidencia-se como em Bento Teixeira, pela primeira vez na literatura portuguesa, Proteu canta ele mesmo. Da garantia de historicidade para a ninfa cantora n'Os Lusíadas, passando por ser autor das poesias amorosas cantadas pelas ninfas no Naufrágio de Sepúlveda, o Proteu da Prosopopeia torna-se personagem madura de um poeta e cantor épico completo. A especifidade desse poeta épico na Prosopopeia, em comparação com os

\footnotetext{
54 TEIXEIRA, 2008, estr. XXI.

55 TEIXEIRA, 2008, estr. LXXII.
} 
modelos em Ariosto ou Camões, encontra-se no fato de a figura de Proteu ser um narrador intradiegético, esboçado como narrador consciente e metarreflexivo. A Prosopopeia insere-se assim numa série de encenações da poesia na épica renascentista portuguesa que desenvolve a figura mítica de Proteu de vaticinador a poeta.

Na investigação, o gênero épico foi contemplado inicialmente sob os seus aspectos históricos, e depois não menos como instrumento de constituição identitária nacional - a análise da figura de Proteu e do seu contexto narrativo demonstra, porém, que episódios como a Ilha dos Amores, como os innamoramenti do Naufrágio de Sepúlveda ou o Canto de Proteu na Prosopopeia ganham sentido quando se tem em conta a dimensão metarreflexiva que a épica portuguesa, como a ibérica no geral, gosta de desenvolver. Nesta empresa, a figura de Proteu representa um papel central.

\section{Referências}

\section{Textos}

ARIOSTO, Ludovico. Orlando Furioso, a cura di Cesare Segre. Milano: Mondadori, 1976.

ARISTOTLE. Problems II. Books XXII-XXXVIII, with an English translation by W.S. Hett. London: Heinemann, 1957.

BOCCACCIO, Giovanni. Genealogie deorum gentilium. In: Tutte le opere VII-VIII. Ed. Vittore Branca. Milano: Mondadori, 1998.

CAMÕES, Luís de. Os Lusíadas. Ed. Emanuel Paulo Ramos. Porto: Porto Editora, 1987.

CORTE REAL, Jerónimo de. Naufrágio de Sepúlveda. In: Obras. Ed. M. Lopes de Almeida. Porto: Lello \& Irmão, 1979. p. 479-877.

NONNOS DE PANOPOLIS. Les Dionysiaques I. Texte établi et traduit par Francis Vian. Paris: Les Belles Lettres, 1976. 
PICO DELLA MIRANDOLA, Giovanni. De la dignité de l'homme. Oratio de hominis dignitate. Traduit du latin et présenté par Yves Hersant. Combas: Éd. de l'Éclat, 1993.

SANNAZARO, Iacobo. Opere volgari. Ed. Alfredo Mauro, Bari: Laterza, 1961.

SANNAZARO, Jacopo. De partu virginis. Il parto della Vergine. Volgarizzamento di Giovanni Giolito de' Ferrari (1588) a fronte. Ed. Stefano Prandi, Roma: Città Nuova, 2001.

SANNAZARO, Jacopo. Latin Poetry [ed. bilingue]. Translated by Michael C.J. Putnam. Harvard: University Press, 2009.

TEIXEIRA, Bento. Prosopopéia. In: Épicos. Ed. Ivan Teixeira, apres. Marcello Moreira. São Paulo: Imprensa Oficial, 2008. p. 95-155.

\section{Estudos}

ALVES, Hélio J. S. Camões, Corte Real e o Sistema da epopeia quinhentista. Coimbra: Centro Interuniversitário de Estudos Camonianos, 2001.

ALVES, Hélio J. S. Corte Real, a evolução da sua arte. Península 2, p. 171-199, 2005.

COSTIGAN, Lúcia Helena. Empreendimento e resistência do cristão-novo face à política de Filipe II: $\mathrm{O}$ processo inquisitorial de Bento Teixeira. Colonial Latin American Review v. 12, n.1, p. 37-61, 2003.

DERAMAIX, Marc. Mendax ad caetera Proteus. Le mythe virgilien de Protée et la théologie poétique dans l'oeuvre de Sannazar. In: Il sacro nel Rinascimento. Atti del XII convegno internazionale (ChiancianoPienza 17-20 luglio 2000), ed. Luisa Rotondi Secchi Tarugi. Firenze: Cesati, 2002. p. 87-105.

FRIEDLEIN, Roger. Indexikalisierung von Wissensinszenierungen in der Renaissance-Epik Portugals. Luís de Camões: Os Lusíadas (1572) und Jerónimo Corte Real: Naufrágio de Sepúlveda (1594). In: Dynamiken des Wissens. Ed. Klaus W. Hempfer \& Anita Traninger. Freiburg i. B.: Rombach, 2007. p. 187-217. 
FRIEDLEIN, Roger. Die Kraft der Poesie - zur Inszenierung erotischer und heroischer Dichtung in Garcilasos Égloga II und Camões' Os Lusíadas, IX-X. In: Arkadien in den romanischen Literaturen. Ed. Roger Friedlein, Gerhard Poppenberg \& Annett Volmer. Heidelberg: Winter, 2008. p. 237-254.

GIAMATTI, A. Bartlett. Proteus Unbound: Some Versions of the Sea God in the Renaissance. In: The Disciplines of Criticism: Essays in Literary Theory, Interpretation, and History. Ed. Peter Demetz et al. New Haven: Yale University Press, 1968. p. 437-475.

NELTING, David. Frühneuzeitliche Pluralisierung im Spiegel italienischer Bukolik. Tübingen: Narr, 2007.

OSKIAN, Giulia. Machiavelli, Montaigne, Charron: Modelli antropologici e sviluppi politici. In: Rinascimento: Rivista dell'Istituto Nazionale di Studi sul Rinascimento, v. 44, p. 251-272, 2004.

PARENTI, Giovanni. Poëta Proteus Alter: Forma e storia di tre libri di Pontano. Firenze: Olschki, 1985.

QUINT, David. Origin and Originality in Renaissance Literature. Versions of the Source. New Haven: Yale University Press, 1983.

SILVA, Anazildo Vasconcelos da; RAMALHO, Christina. História da Epopéia Brasileira. Teoria, crítica e percurso. Rio de Janeiro: Garamond, 2007.

SILVA, Vítor de Aguiar e. Função e Significado do episódio da 'Ilha dos Amores' na estrutura de 'Os Lusíadas'. In: Camões: Labirintos e Fascínios. Lisboa: Cotovia, 1994. p. 131-143.

WOLF, Werner. Metaisierung als transgenerisches und transmediales Phänomen: Ein Systematisierungsversuch metareferentieller Formen und Begriffe in Literatur und anderen Medien. In: Metaisierung in Literatur und anderen Medien. Ed. Janine Nadj et al. Berlin: De Gruyter, 2007. p. 25-64. 


\section{Resumo}

A figura do deus mitológico Proteu, conhecida na literatura antiga e do Renascimento pela sua capacidade de transformação, é usada de preferência em contextos marcados pela autorreflexividade. Assim, na épica portuguesa de Quinhentos, ele faz a sua primeira aparição no episódio da Ilha dos Amores (Lusíadas, IX-X), onde forma parte de uma complexa encenação narrativa em que se reflete acerca da poesia lírica e épica. A sua potencialidade metarreferencial será plenamente desenvolvida em Jerônimo de Corte Real: Naufrágio de Sepúlveda, e em Bento Teixeira: Prosopopeia, onde Proteu se torna imagem do poeta melancólico e do cantor épico. A partir daqui, pode-se identificar também um modelo concreto da Prosopopeia na literatura italiana renascentista.

\section{Résumé}

Dans la poésie épique de l'antiquité et de la Renaissance italienne, le personnage mythologique de Protée est connu pour sa capacité extraordinaire de transformation, qui rend ce personnage idoine a être utilisé dans des contextes autoréflexifs. Ainsi il fait sa première apparition dans l'épique portugaise du seizième siècle dans l'épisode métaréférentiel de l'île des Amours camonienne (Os Lusíadas, IX-X), où il fait partie d'une mise en scène complexe de la poésie. Dans Jerónimo de Corte-Real: Naufrágio de Sepúlveda et Bento Teixeira: Prosopopeia, le potentiel métaréférentiel du personnage sera pleinement développé. Protée y représente l'image du poète mélancolique ou bien du chanteur épique. Sur cette base on pourra identifier également un modèle concret de la Prosopopeia dans la littérature italienne de la Renaissance. 